\title{
ВЛИЯНИЕ ЦИФРОВОЙ ЭКОНОМИКИ НА ПРОЦЕССЫ БАНКОВСКОГО СЕКТОРА
}

\author{
(c) 2020 Понырко Руслан Михайлович \\ аспирант, Финансовый факультет \\ Финансовый Университет при правительстве РФ, Россия, Москва \\ E-mail: ruslanponyrko@yandex.ru
}

В статье проанализированы ведущие направления развития механизма цифровизации экономики. В качестве результатов исследования выделена значимость цифровых технологий в цепочке создания стоимости. Результаты исследования могут быть применены при формировании стратегии хозяйствующих субъектов в условиях цифровизации.

Ключевые слова: банковская активность, деловой цикл, параметры цикла, диджитализация, финтех, искусственный интеллект, машинное обучение, стратегия цифровизации, банковские экосистемы.

Цифровую трансформацию можно определить как повсеместную взаимосвязь всех секторов экономики и как адаптацию действующих лиц к новым ситуациям в цифровой экономике. Решения в этих взаимосвязанных системах охватывают обмен и анализ данных, расчет и оценку вариантов, а также инициирование действий и планирование последствий. Следовательно, очевидна важность в новых ситуациях и тот факт, что также могут иметь место последствия, которые необходимо спрогнозировать.

Одним из основных факторов цифровизации, по-видимому, является закон Мура и цифровая амортизация, представленные Маком [5]. Закон, с одной стороны, касается экспоненциального роста числа транзисторов в плотной интегральной схеме компьютерного чипа и последующего увеличения вычислительной мощности. Сам закон существует уже давно и, похоже, его актуальность в будущем подойдет к концу, поскольку число транзисторов в плотной интегральной схеме компьютерного чипа растет таким экспоненциальным образом, что компьютерные компании не способны производить всегда меньшие и более быстрые компьютерные чипы.

Увеличение более коротких жизненных циклов, обусловленное технологическим износом, требует большей гибкости при разработке продукта, индивидуализации по требованию, децентрализации и расширения возможностей для более быстрого принятия решений и более эффективного распределения ресурсов.

Russmann смог выявить актуальные технологические тренды как представителей цифро- вых технологий в Индустрии 4.0, исследователь считает:

1) Большие данные и аналитика - это сила. Сбор и всесторонняя оценка данных из разных источников является ключевым. Это позволяет проводить принятие решений в режиме реального времени.

2) Автономные роботы, которые выполняют широкий спектр основных и однообразных и сложных и разнообразных задач. Роботы могут даже взаимодействовать друг с другом.

3) Горизонтальная и вертикальная системная интеграция - это ИТ-система, обеспечивающая доступ ко всей цепочке создания стоимости и объединяющая различные отделы для поддержки сквозного процесса [8].

С другой стороны, цифровая трансформация представляется организационным изменением для многих отраслей финансового сектора и почти для всех кредитных организаций в России. Данная трансформация - это изменение, которое происходит быстрее, чем любое изменение ранее, что означает для банков необходимость переизобретать некоторые части своей организационной структуры.

Стратегии цифровой трансформации

Согласно Matt, многие финансовые компании уже осознали необходимость качественной адаптации к цифровизации экономики и новым технологиям. Предполагается, что путем преобразования цифровых стратегий получится лучше справляться с изменяющейся корпоративной средой и оставаться конкурентоспособными. Многие инициативы по исследованию 
новых цифровых технологий включают преобразования ключевых бизнес-операций и влияют на продукты и процессы, а также на организационные структуры и концепции управления. Формулирование центральной концепции для интеграции всей координации, расстановки приоритетов и реализации цифровых преобразований внутри компании является ключевой задачей высшего руководства.

Matt подразделяет корпоративную стратегию на два типа, как показано на рисунке ниже. С одной стороны, существуют операционные стратегии, которые касаются продуктов, рынков и процессов. С другой стороны, существуют функциональные стратегии, ориентированные на финансы, человеческие ресурсы и ИТ.

В эпоху цифровых стратегий трансформации, однако, акцент делается на адаптацию и перестраивание как продуктов, с одной стороны, так и организационных аспектов, а с другой, в связи с характером новой технологии, в цифровой трансформации - это больше вопрос о том, как именно новая технология меняет пользовательский интерфейс, а не о том, как меняется продукт и процесс [2].

Matt определил в своей исследовательской работе четыре важнейших и взаимодействующих показателя в стратегии цифровых преобразований. Это использование технологий, изменения в создании стоимости, структурные изменения и финансовые аспекты.

Внедрение технологий зависит от мотивации и способности финансовой организации разрабатывать новые технологии и ИТ-системы, инвестировать в них. В то же время основной является возможность использовать технологию с высокой экономической эффективностью. Таким образом, компания устанавливает технологического лидера, который задает новые стандарты, или просто использует инновационные технологии, чтобы иметь возможность конкурировать со своими соперниками на рынке.

Роль цифровых технологий и их влияние на перспективы развития банковского сектора

После эволюции Интернета, мобильной связи и Интернета вещей, новые драйверы, такие как искусственный интеллект и большие данные, стали предметом внимания бизнеса. Благодаря этим инновациям экономика может преодолеть не только физические, но и интеллектуальные, и творческие ограничения, например, увеличить продажи, благодаря более широкому знанию клиента и более сосредоточенному на нем вниманию.

Соответственно, текущие события могут быть поняты как одно из самых фундаментальных событий для общества и экономики.

Для термина «искусственный интеллект» не существует общепринятого определения до сих пор. С одной стороны, Негневицкий начал с изменения определения термина «интеллект» как способности кого-то узнавать и изучать вещи. Он указал, что не определено, обладает ли кто-то или что-то способностью, поэтому это может быть человек или интеллектуальный компьютер, пока есть эффект обучения. По его словам, термин «искусственный интеллект» может быть определен как наука, которая фокусируется на разработке машин для выполнения задач и вещей, которая нуждается в интеллекте, если это делается людьми [3].

Многие исследователи определяют искусственный интеллект как способность абстрактного и комбинированного мышления и выводить из него действия с помощью алгоритмов. Кроме того, Фишер и другие ученые утверждают, что искусственный интеллект может применяться в агентских или многоагентных системах, которые могут выполнять задачи в постоянно меняющейся среде. Это пример того, как алгоритм может извлечь уроки из предыдущих задач и приспособиться к внешнему миру.

Искусственный интеллект пытается представить человеческий интеллект с использованием алгоритмов и компьютеров. Искусственный интеллект имеет дело с различными предметами, такими как знания, обучение, принятие решений, рассуждения и многое другое.

Искусственный интеллект можно охарактеризовать как автоматизацию интеллектуального поведения и относит часть к области информатики и как машины, которые выполняют задания, которые потребовали бы интеллекта, если бы их выполняли люди.

В целом, нет конкретного и устоявшегося определения термина искусственный интеллект. В данной магистерской работе в качестве основного следует выделить определение о том, что искусственный интеллект использует алгоритмы и компьютерные технологии, чтобы попытаться представить поведение человека там, где необходим интеллект.

Соответственно, технический прогресс под- 
талкивает сегодняшний бизнес в новое направление с использованием цифровых инноваций, таких как большие данные или искусственный интеллект. Нынешняя организационная модель плавно превращается в алгоритмическую.

Gartner упоминает в своем отчете, что искусственный интеллект в настоящее время является одной из главных технологических тенденций. Для компаний важно скорректировать бизнесмодели и учитывать потенциальное влияние этих тенденций на бизнес при принятии решения о преобразовании их организации. Более того, Gentsch утверждает, что смарт-способ использования данных важен, поскольку он также является связующим звеном для автоматизации и оптимизации функций и процессов для повышения эффективности и получения конкурентного преимущества [7].

Цифровизация преобразует бизнеспроцессы, чтобы предоставить более точные и в реальном времени представления о продуктах, услугах и материалах. Соответственно, важна реорганизация процессов, связанных с внедрением новых технологий.

Поскольку область исследований является относительно новой для научных кругов, существует не так много специализированной литературы по искусственному интеллекту. А точнее, меньше литературы о применении искусственного интеллекта в бизнес-процессах. Однако за последние годы количество публикаций увеличилось.

В целом публикации, касающиеся искусственного интеллекта, в основном фокусируются на субъективно-технологических аспектах, а не на управленческих.

Было найдено одно исследование, в котором сообщалось о концепциях алгоритмического маркетинга и разговорного офиса в сфере продаж и маркетинга, которые могут быть использованы для повышения эффективности продаж компаний и взаимоотношений с клиентами. Каждое технологическое развитие, тенденция или инновация имеют разные движущие силы и факторы успеха реализации. Давенпорт и Ронанки отмечают, что с использованием искусственного интеллекта можно сделать несколько улучшений, например, улучшить финансовые показатели, сократить затраты и время, а также повысить удовлетворенность клиентов. Поскольку эти факторы в настоящее время находятся в центре внимания бизнеса, искусственный интеллект является потенциальным инструментом.

Концепция искусственного интеллекта очень сложна, и поэтому важно подчеркнуть, что искусственный интеллект основан на различных алгоритмах обучения, которые реализованы в одной системе.

Существует три различных типа обучения: символический искусственный интеллект, субсимволический искусственный интеллект и машинное обучение. Кроме того, машинное обучение должно быть разделено на контролируемое обучение, обучение без учителя и обучение с подкреплением. Тем не менее, это более или менее используется только научным сообществом, потому что различные методы обучения влияют друг на друга [7].

Интеллектуальный анализ данных является последним примером символического искусственного интеллекта. Эта прикладная область представляет собой метод структурирования собранных необработанных данных в соответствии с определенной моделью интеллектуального анализа данных и их иллюстрации в качестве основы для принятия решений.

Часто используемым синонимом субсимволического искусственного интеллекта является нейронный искусственный интеллект, который часто ассоциируется с глубоким обучением. Точно так же Miikkulainen определяет субсимволический искусственный интеллект как представление знаний, основанное на корреляциях. Это означает, что повторяющаяся проблема решается с использованием наиболее значимых действий, основанных на предыдущих решениях.

Машинное обучение - это термин, который привлекает все большее внимание исследований и общества, и является одной из будущих тенденций в области искусственного интеллекта. Ключевой концепцией машинного обучения является получение знаний из прошлого опыта и принятие будущих решений на основе этого опыта. Одним из примеров является то, что интеллектуальный анализ данных является наиболее важным вариантом использования машинного обучения. Кроме того, люди делают ошибки во время анализа или интерпретации огромных массивов данных. Эти ошибки можно устранить, используя машинное обучение для анализа данных.

В целом, задача алгоритма контролируемого обучения состоит в том, чтобы обнаружить взаимосвязь между входными и выходными данны- 
ми и извлечь из них уроки [7].

Коциантис объяснил контролируемое обучение как принятие набора правил из алгоритмов машинного обучения. Как правило, это означает, что разработчики определяют четкие структуры в алгоритме, чтобы влиять на ход обучения, а также на принимаемые решения [4].

В отличие от контролируемого обучения, неконтролируемое обучение не имеет ранее определенных целей. Здесь цель состоит в том, чтобы алгоритм машинного обучения независимо выявлял сходства и различия в наборе данных. Эти алгоритмы строят кластеры в соответствии с наблюдаемыми данными и могут быть использованы, например, для задач сегментации клиентов или рынка.

Кроме того, эти алгоритмы могут использоваться для инициализации глубоких нейронных сетей, как упоминалось в других исследованиях. Более того, принципиально, что обучение без учителя позволяет извлекать уроки из сложных проблем и является высоко адаптивным к изменяющимся обстоятельствам.

Преимущество этой системы заключается в том, что перед выбором наиболее подходящего решения принимается во внимание множество неопределенных факторов окружающей сред. Kaelbing, Littmann и Moore заявили, что обучение с подкреплением должно изучать естественное поведение для данной проблемы с использованием метода проб и ошибок в условиях изменяющихся условий окружающей среды. Обучение с подкреплением является наиболее развитым типом машинного обучения, и сегодня не так распространено, но оно станет в будущем [6].

Цифровизация также затронула и организацию работы подразделений организаций, таким образом были внедрены цифровые рабочие места.

Очевидно, что внедрение новых инструментов также требует, чтобы работники умственного труда обладали навыками, чтобы не отставать от сложности рабочих мест и уметь мыслить абстрактно для решения проблем. Изменения в дизайне рабочих мест объясняются более слож- ными проблемами в деловой жизни, которые могут быть решены только с помощью командной работы, гибкого принятия решений и эффективных процессов.

При переходе от базовой интрасети к полностью цифровому рабочему месту необходимо продумать четыре этапа. Этот путь простирается от портала, который предлагает информацию в форме самообслуживания для сотрудников соответствующих компаний, до целостного портала, который интегрирует различные приложения, гарантирует, что возможны новые методы работы, и что долгосрочная трансформация сотрудничества закреплена в культура компании.

На этих четырех этапах становится очевидным, что преобразование идет от очень технических решений, основанных на предоставлении информации в целостных условиях, которые также охватывают социально-экономические аспекты совместной работы.

Особенно интересен драйвер для полноценного цифрового рабочего места. Первостепенные изменения, культура и приверженность необходимы при реализации полноценного цифрового рабочего места. Гейслер и Крузе описывают подобное явление. Оба автора утверждают, что дискуссии об оптимальной поддержке работников умственного труда были сосредоточены на самых основных аспектах в последующие годы.

В результате цифрового преобразования:

1) цепочки создания стоимости будут фрагментированы, поскольку новые технологии сделают процессы создания стоимости более прозрачными;

2) появятся новые экосистемы, поскольку фрагментация цепочки создания стоимости и конвергенция отрасли начнут поддерживать формирование платформ или сетей создания стоимости;

3) автоматизация, цифровизация, киберфизические системы на интеллектуальных фабриках и искусственный интеллект окажут существенное влияние на рабочие процессы.

\section{Библиографический список}

1. Балакин И.А. Влияние цифровизации на организаонную структуру банков // Modern Science.-2019 г.№ 4-1.- С. 94. 
2. Галанова А.К.Цифровизация управления банков // Экономика России в современных условиях: пути инновационного развития и повышения конкурентоспособности Сборник научных трудов по итогам всероссийской научно-практической конференции молодых ученых Санкт-Петербургского государственного экономического университета. - 2017 г.-С. 124-126.

3. Долгушина А.Я. Основные направления развития цифровизации банковской деятельности // В сборнике: От синергии знаний к синергии бизнеса Сборник статей и тезисов докладов IV Международной научнопрактической конференции студентов, магистрантов и преподавателей. - 2017 г. - C. 153-156.

4. Дятлова А.О.Направления развития банков в условиях цифровизации экономики // В сборнике: банки и финансы в условиях цифровизации экономики Сборник статей Международной научно-практической конференции для студентов специалитета, бакалавриата и магистратуры Научное электронное издание.2019 г.-С. 19.

5. Зайцева И. Г. Развитие цифровых технологий в банковской сфере // В сборнике: Развитие финансовых отношений в период становления цифровой экономики. - 2019 г. - С. 188.

6. Князева И. В. Повышение эффективности работы с клиентами в условиях цифровизации деятельности банков // Трансформация банков в условиях цифровой экономики Сборник научных трудов студентов и аспирантов. - 2018 г.-С. 192-198.

7. Gentsch P. Kunstliche Intelligenzfiir Sales, Marketing und Service: Mit Al und Bots zu einem Algorithmic BusinessKonzepte, Technologien und Best Practices // Springer. - 2017._ P. 34.

8. Russmann M. Industry 4.0: The future of productivity and growth in manufacturing industries // Boston Consulting Group.-2015. - P. 43. 